\title{
COMPUTATIONAL ANALYSIS OF LOAD VENTILATION IN BROILER TRANSPORT
}

\author{
Daniel G. Pinheiro" ${ }^{1}$, Nítalo A. F. Machado ${ }^{1 *}$, José A. D. Barbosa-Filho1, Iran J. O. Da Silva²
}

${ }^{1 *}$ Corresponding author. NEAMBE - Department of Agricultural Engineering - DENA/ UFC/ Fortaleza - CE, Brazil. E-mail: nitalo.farias@ufma.br | ORCID ID: https://orcid.org/0000-0002-4967-2620

\author{
KEYWORDS \\ poultry, animal \\ welfare, CFD \\ simulation, precision \\ livestock farming.
}

\begin{abstract}
The characterization of ventilation during the transport of broiler chickens is essential for identifying and characterizing the potential problems of a convective heat flow and its effects on the welfare and the health and production conditions of the chickens. The objective of this study was to evaluate the ventilation patterns in two layout models of a live transport load: conventional (LC) and alternative (LA) with spacers placed between the chicken transport crates. Computational fluid dynamics (CFD) simulations and wind tunnel tests were performed using small scale models. The results showed that the use of spacers between crates (LA model) modified the ventilation patterns and increased the wind circulation between crates. However, wind tunnel tests simulating a density of eight birds/crate were inconclusive because the ventilation was below the sensitivity of the measuring devices used $(0.001 \mathrm{~m} / \mathrm{s})$. It can be concluded that the use of spacers between the transport crates can modify the ventilation patterns within the load and increase the air circulation between the crates. However, the internal ventilation within the crates has not changed, suggesting the need for studies on the aerodynamics of a transport crate for poultry use.
\end{abstract}

\section{INTRODUCTION}

Transport is considered one of the most critical points related to animal welfare, survival and condemnation of poultry carcasses in the broiler production chain (Barbosa-Filho et al., 2014; Santos et al., 2020). The thermal environment of livestock transport is generally considered one of the main problems related to welfare and production losses from dead on arrivals (DOAs) (Vieira et al., 2019). This is due to the interaction of multiple environmental variables of the load during transport, resulting in the production of "thermal cores" (BarbosaFilho et al., 2014), particularly those related to the accumulation of relative humidity and ventilation failure (Mitchell \& Kettlewell, 1994).

Unlike an inert load, the transport of live chickens is complex because chickens emit approximately $120 \mathrm{~W}$ of heat (Kettlewell et al., 2001) and continuously adapt physiologically in an attempt to maintain their thermal balance through thermoregulatory mechanisms (SouzaJunior et al., 2019). The main thermal transfer route physiologically is the evaporative route, which can be seriously compromised by the elevation of the ambient temperature and accumulation of relative humidity of the air, in the microclimate in which it is inserted (Gonçalves et al., 2017). The renewal of air inside the load can be an efficient and viable solution to reduce/dissipate the accumulation of water vapor and thermal energy during livestock transport (Norton et al., 2013).

An interesting strategy for mitigating heat stress problems in the transport compartment would be to use ventilation resulting from the animal transport itself. The moving of the load during transport will promote air circulation inside the crates, which can be used continuously to reduce the impact of thermal stress during this operation (Gilkeson et al., 2016). With air renewal, improvements in the thermal comfort and welfare of the birds are an expected result, considering the reduction in the number of DOAs and problems related to the final quality of the meat (Spurio et al., 2016).

A computational simulation based on computational fluid dynamics (CFD) has recently been considered a powerful tool in investigations related to the heat transfer of animals through convection (Norton et al., 2013; Gilkeson et al., 2016; Seedorf \& Schmidt, 2017). The use of CFD and

${ }^{1}$ NEAMBE - Department of Agricultural Engineering - DENA/ UFC/ Fortaleza - CE, Brazil.

${ }^{2}$ NUPEA - Department of Biosystems Engineering - ESALQ/ USP/ Piracicaba - SP, Brazil.

Area Editor: Danilo Florentino Pereira

Received in: 8-17-2020

Accepted in: 10-21-2020 
small-scale models in wind tunnel tests on projects or a problem analysis has been increasing owing to reduced costs, an increase in the processor performance, and advances in computer simulation software (Wehmann et al., 2017).

In this context, in the present study, the internal ventilation patterns of a broiler transport load were evaluated using CFD techniques, and the use of spacer devices specifically designed to create air circulation corridors between chicken transport crates was tested using a layout model conventionally applied in Brazilian broiler farming.

\section{MATERIAL AND METHODS}

A real database on the technical and environmental information of chicken transport was obtained through the monitoring of ten journeys. The distance between the farm and abattoir was $35 \mathrm{~km}$, and monitoring was carried out from February 15 to September 7, covering the dry and rainy seasons of 2017 in the municipality of Beberibe, Ceará State, in northeastern Brazil. The journeys occurred during the morning shift between 05:00 and 07:00. The recording of the temperature $\left(\mathrm{TA},{ }^{\circ} \mathrm{C}\right.$ ) and relative humidity $(\mathrm{RH}, \%)$ data from the external environment during transport were recorded every 10 min using data loggers (Onset, U23-001 HOBO Pro v2, Massachusetts, USA) installed above the

A

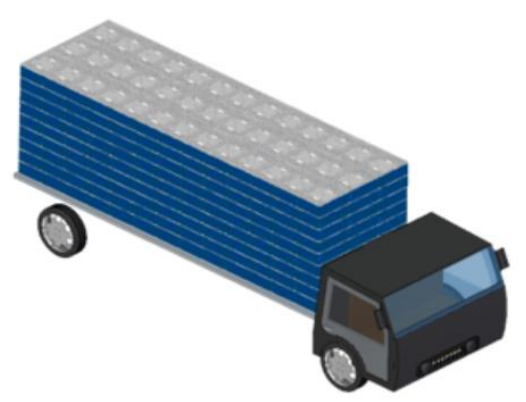

truck cabin. The average speed was recorded as $72 \pm 4.5$ $\mathrm{km} / \mathrm{h}$. The radiation was obtained by the station 82397 Fortaleza (349'12 "S 38³2'24" W and 29.89 m of altitude) of the National Institute of Meteorology of Brazil (INMET). The following were considered as input data in the simulation system: the average transportation speed, TA, and $\mathrm{RH}$ of the external environment during the journey period, which took approximately $30 \mathrm{~min}$. For the design of the virtual model of the crates and the spacer devices, we considered the dimensional and structural information of a real crate model used for transport of the broiler chickens.

\section{Treatments}

In this study, the effect of using the spacer devices between the crates used for the transport of chickens was tested. The tests were conducted using the conventional layout model (LC), where crates are arranged transversally in the load, organized in three columns, and distributed in rows along the truck deck assuming the shape of a rectangular prism (Figure1A). The results were compared with an alternative model (LA), which had the same layout as the LC crates but equipped with spacer devices designed to create air circulation corridors between the transport crates (Figure 1B).

B

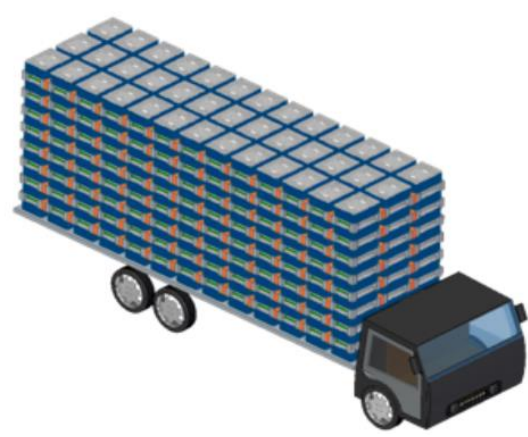

FIGURE 1. Virtual models: conventional (A) and alternative with spacer devices (B).

\section{Virtual Models}

The modeling of the crate used to transport the broilers and the spacer was conducted using Solid Edge ST10 software. The design of spacer a tray design consisting of four support columns, two 230-mm bars, two 630-mm bars, and four bungs for column support was chosen. The objective of the spacers was to form horizontal and vertical corridors between the crates used for transporting the chickens, as shown in Figure 2. The devices were subjected to a stress-strain analysis using the Solid
Edge ST10 computational environment. Concerning the virtual models of the load layouts in the CFD simulation, there was a reduction in the load regarding the number of crates, which went from 350 to 280 , but without changes to the characteristic configurations of each model. These adaptations and simplifications were necessary because of processing limitations (hardware), because the simulations reached the maximum capacity of the computer, not reaching convergence. However, the geometric pattern of the cargo has been preserved, guaranteeing genuine results. 


\section{Spacer device}

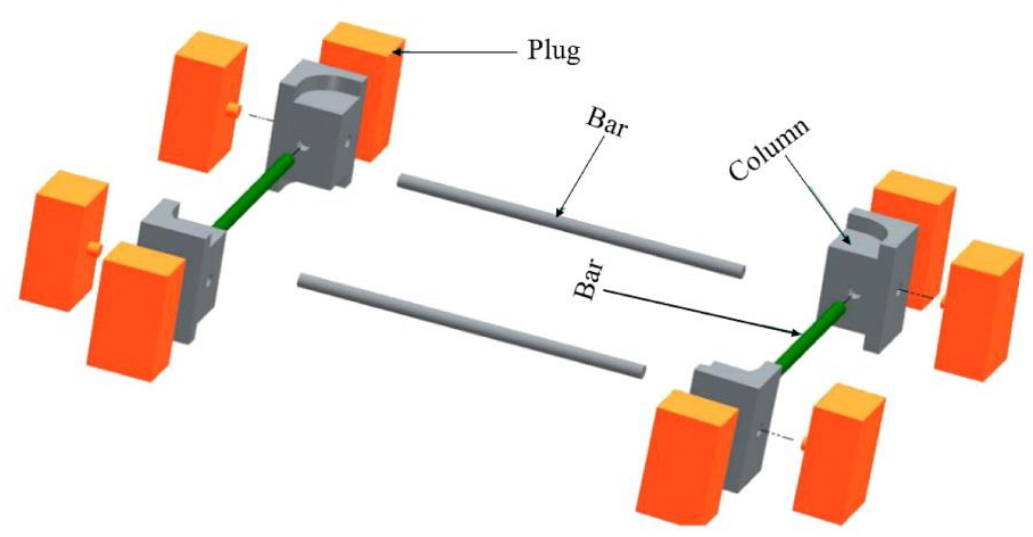

Using the spacer device
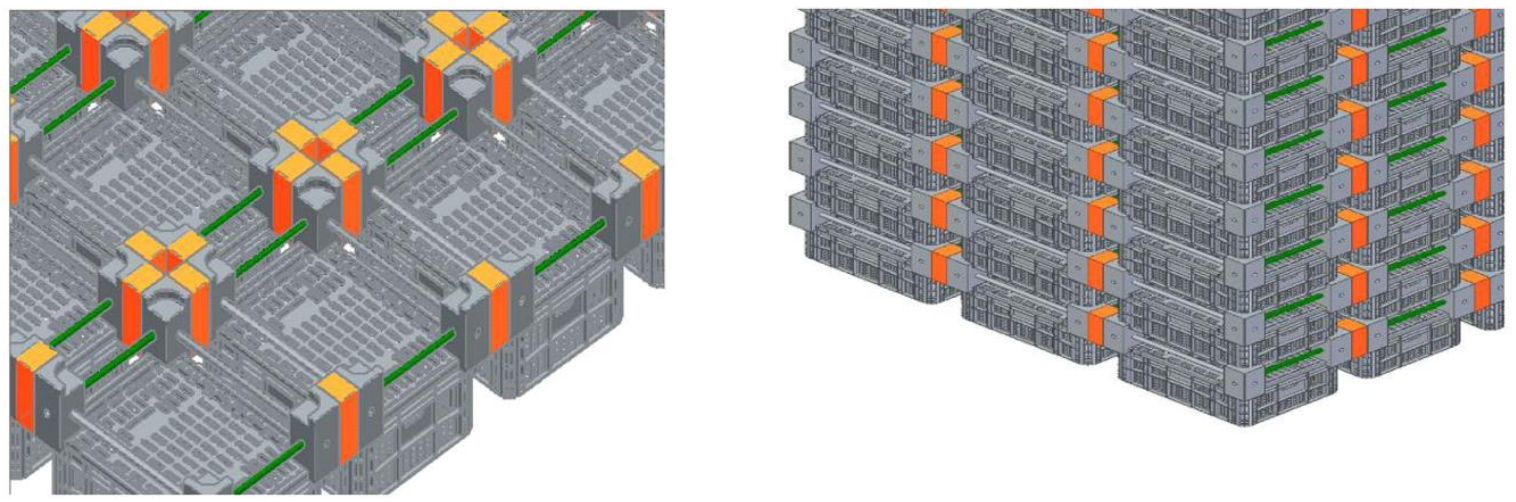

FIGURE 2. Virtual model in perspective of the spacer device (A) and representation of the assembly of the spacers in the transport crates (B).

\section{CFD Simulation}

Once the geometric plane was defined, and using the assembly of the simplified virtual models at the real scale, computational simulation tests were conducted. The CFD software package used during this study was SolidWorks Flow Simulation. The SolidWorks Flow Simulation is a robust and user-friendly complement to SolidWorks, ver.2015, which uses the finite volume method in an automatically developed computational mesh to solve timedependent Navier-Stokes equations and was used in this study as a CFD tool. This method is among the preferred methods for modeling fluid phenomena (Ahmadi \& Sefidvash, 2018).

An adaptive mesh generation was used in the process of adapting the computational mesh to the solution during the calculation. The mesh generation comprises the process of decomposing the total volume into smaller volumes, allowing the use of the finite volume method. In this study, we used the automatic mesh generator of the software, using hexahedral cells structured in most of the domain, except around the truck, where tetrahedral cells were used, but with refinement in the layers along the surface of the truck to solve the flow problem of the boundary layer near the diffuser wall. The number of knots in the mesh was 89.603 , resulting in a maximum orthogonal quality of $89.60 \%$. For a better estimate of minimum layer height (White, 2000) theory of limit layer for flat plates was considered. The boundary conditions were designed to simulate the real flow conditions during the transport. The boundary conditions used in the model are shown in Table 1 . These conditions were established with the real monitoring of broiler chicken journeys.

TABLE 1 . Boundary conditions.

\begin{tabular}{lc}
\hline Variables & Values \\
\hline Prescribed speed $(\mathrm{m} / \mathrm{s})$ & 20 \\
Temperature $\left({ }^{\circ} \mathrm{C}\right)$ & 25 \\
Relative humidity $(\%)$ & 75 \\
Radiation $\left(\mathrm{Kj} / \mathrm{m}^{2}\right)$ & 420 \\
Atmospheric pressure $(\mathrm{mm} \mathrm{Hg})$ & 760 \\
\hline
\end{tabular}

SolidWorks Flow Simulation extends the solutionadaptable refinement procedure to the computational domain regions to obtain more accurate and optimized CFD simulations for mesh generation. Using this software, the mass, momentum, energy, and concentration equations were solved to determine the patterns of the load ventilation in a three-dimensional computational space. The general conservation convection-diffusion equation can be described using [eq. (1)].

$$
\frac{\partial \phi}{\partial t}+\frac{\partial u_{j} \phi}{\partial x_{j}}=\frac{\partial}{\partial x_{j}}\left(\Gamma_{\phi} \frac{\partial \phi}{\partial x_{j}}\right)+S_{\phi}
$$


In which,

$\phi$ stands for the variables of interest, which can be the three velocity components $u(\mathrm{~m} / \mathrm{s})$, temperature $\mathrm{T}\left({ }^{\circ} \mathrm{C}\right)$, contaminant concentration $\mathrm{c}(\mathrm{kg} / \mathrm{kg})$, age of air $\theta(\mathrm{s})$, turbulent kinetic energy $\mathrm{k}_{\mathrm{t}}\left(\mathrm{m}^{2} / \mathrm{s}^{2}\right)$, and dissipation of turbulent kinetic energy $\varepsilon\left(\mathrm{m}_{2} / \mathrm{s}^{3}\right)$, and where $\Gamma_{\phi}$ and $S_{\phi}$ represent the diffusion coefficient and source term of $\phi$, respectively.

\section{Wind tunnel tests}

A prototype truck (length $450 \mathrm{~mm}$, width 400 and height $350 \mathrm{~mm}$ ) was built at a 1:10 scale, and the crates used to transport the chickens were manufactured at the same scale using a modeling through the deposition of a cast material with a 3D printer (XYZ DAVINCI PRO) using lactic acid. The tests had an average duration of $40 \pm 3 \mathrm{~min}$, simulating empty crates and crates full of chickens in a wind tunnel with a test area of $500 \mathrm{~mm} \times 500 \mathrm{~mm}$ with speeds of $10,15,20$, and $30 \mathrm{~m} / \mathrm{s}$. Ten repetitions were performed in the tests. To simulate a density of eight chickens per crate, they were filled with Styrofoam, simulating a volume of approximately eight $2.5 \mathrm{~kg}$ birds. The intra-cage ventilation (ICV, $\mathrm{m} / \mathrm{s}$ ) was measured every minute using thermistor sensors with a measurement sensitivity of $0.001 \mathrm{~m} / \mathrm{s}$, which is distributed as shown in Figure 3. The ICV results were subjected to a non-parametric analysis using the Kruskal-Wallis test $(\mathrm{P}<0.05)$ through the SAS NPAR1WAY procedure (SAS Inst. Inc., Cary, NC).
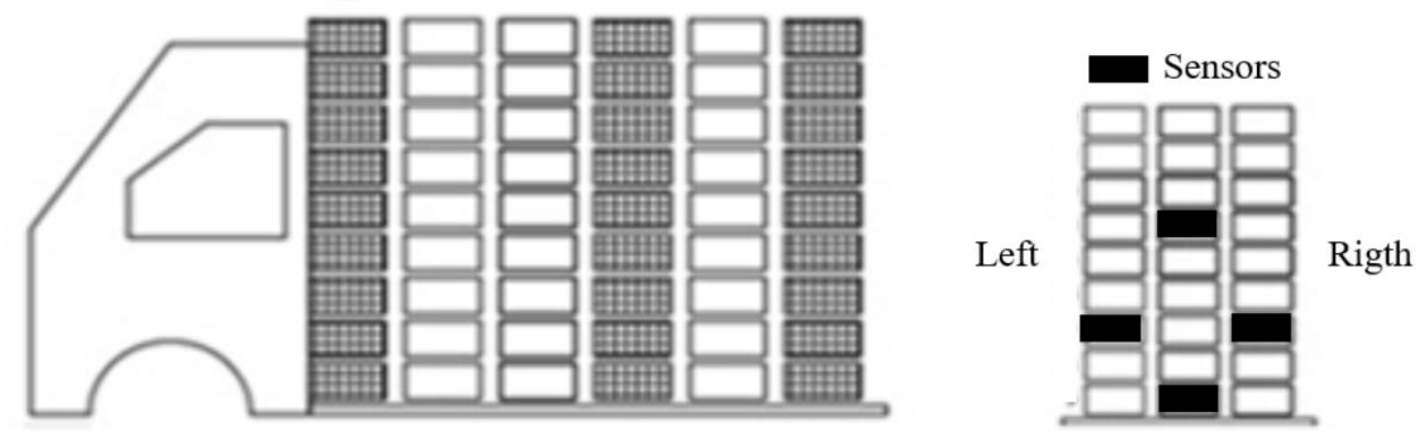

FIGURE 3. Distribution of sensors in the wind tunnel tests.

\section{RESULTS AND DISCUSSION}

\section{Spacers}

The spacer devices withstand a plastic deformation stress of up to $0.3 \mathrm{Mpa}$ (Figure 4A), and consequently tolerate a vertical pressure of approximately $750 \mathrm{~kg}$. Considering the average weight of a full $20 \mathrm{~kg}$ crate (with eight $2.5 \mathrm{~kg}$ birds in each crate, as recommended in Brazil), it would be possible to stack up to 37 crates. However, the transport load does not exceed 13 stacked crates of $\sim 260 \mathrm{~kg}$ (Rui et al., 2011). Therefore, the spacer had a mechanical resistance that meets the requirements of an actual broiler transport. However, the maximum deformation was 0.53 $\mathrm{mm}$ prior to rupture (Figure 4B). This low value can be explained by the solid design of the spacer device, which is necessary to ensure the rigidity and stability while stacking the crate (Pinheiro et al., 2020). The use of spacers between the crates to transport the chickens is aimed at establishing horizontal and vertical flows of $150 \mathrm{~mm}$ along the entire length of the load. The value of $150 \mathrm{~mm}$ was defined based on the maximum dimensions of the load as accepted by the Brazilian National Traffic Council (CONTRAN, 2006), i.e., up to a height of $2.60 \mathrm{~m}$ and a width of $4.40 \mathrm{~m}$. 

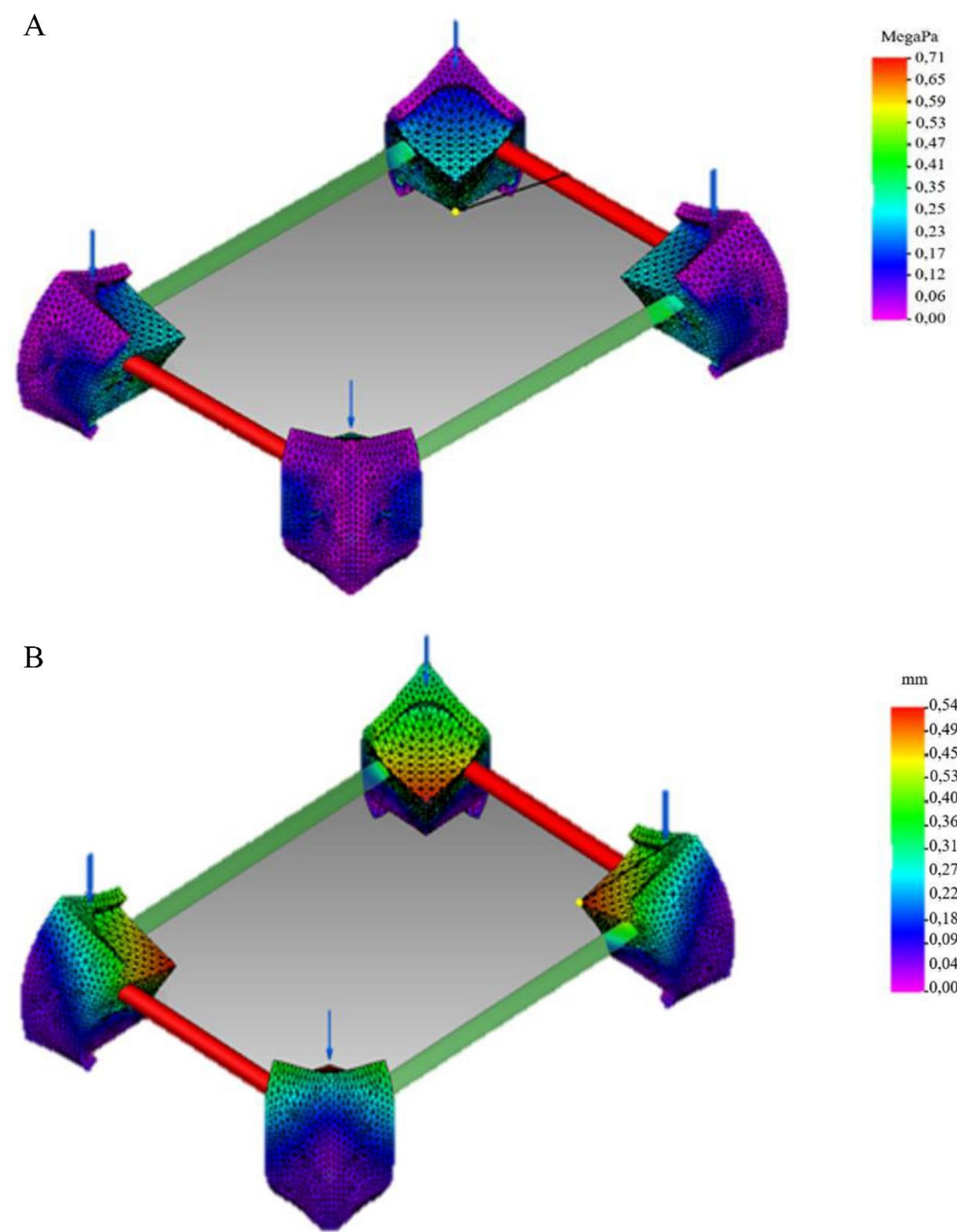

$\mathrm{mm}$

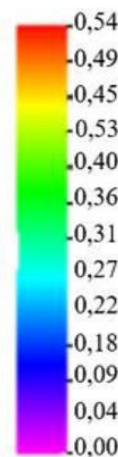

FIGURE 4. Test of stress (A) and deformation (B) of the spacer device

\section{Simulation of CFD}

During the transport of broiler chickens, the wind loses much of its energy when colliding with the front structure of the vehicle (cabin and load). In the LC, after a shock to the front structure, the ventilation reduces its average speed from 22 to $12 \mathrm{~m} / \mathrm{s}$ (a $45.5 \%$ reduction). Most of the ventilation is directed to the sides of the vehicle, with speeds varying from $1.56 \mathrm{~m} / \mathrm{s}$ to $10.80 \mathrm{~m} / \mathrm{s}$ (Figure $5 \mathrm{~A}$ ). A regime of airflow displacement characterized by dragging in the vortices outside the load is observed, except in the rear region where a suction pattern of ventilation toward the interior of the load occurs, (Figure 5B). At this point, there is high turbulence from the pressure gradient of this region of the load (Kettlewell et al., 2001; Gilkeson et al., 2009). However, the ventilation cannot circulate efficiently within the load owing to the compact arrangement of crates used for transporting the broilers (Figure 5B). 


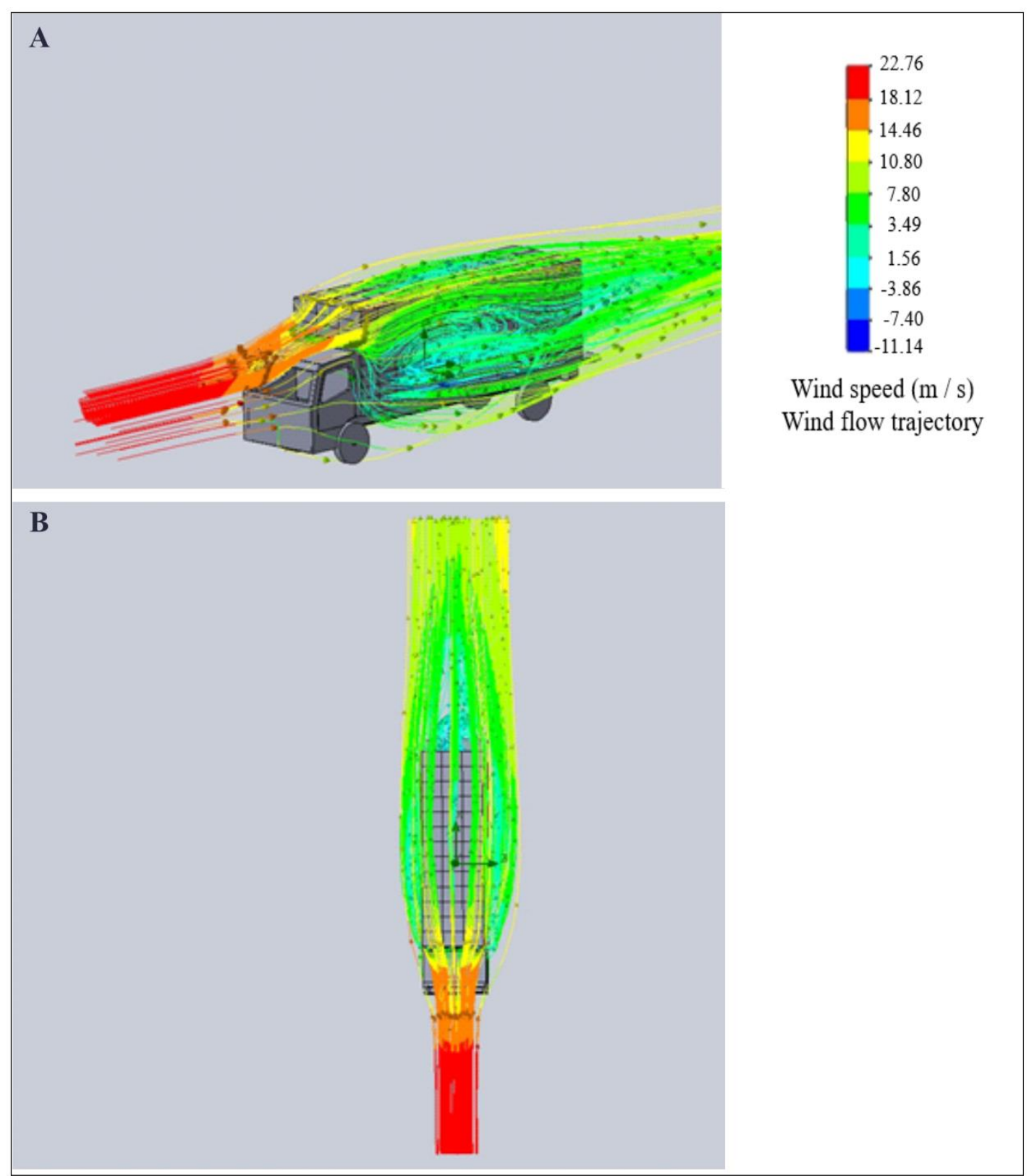

FIGURE 5. Ventilation pattern in the conventional layout (LC) used to transport live chickens, (A) front and side view, (B) top view.

The use of spacer devices in the LA caused a reduction in the average wind speed from 22 to $14 \mathrm{~m} / \mathrm{s}$ (a $36.36 \%$ reduction) after the shock to the frontal structure. Similar to the LC, most of the ventilation after the collision with the cabin is directed toward the sides of the vehicle. However, it was noted that there is a more uniform distribution of wind in front of the load (above the cabin of the truck) and a greater penetration of the ventilation inside the load, with a speed of close to $1.71 \mathrm{~m} / \mathrm{s}$, as represented by the blue lines coming out of the load in Figure 6A and B. In addition, it was observed that there is greater wind displacement into the load by suction in the lateral and rear regions of the vehicle, marked by a turbulent vortex regime into the load, as shown in Figure 6B. The reason for this can be attributed to the higher wind intake from the front of the load by increasing its height and to the horizontal ventilation corridors formed through the use of the spacer devices. 


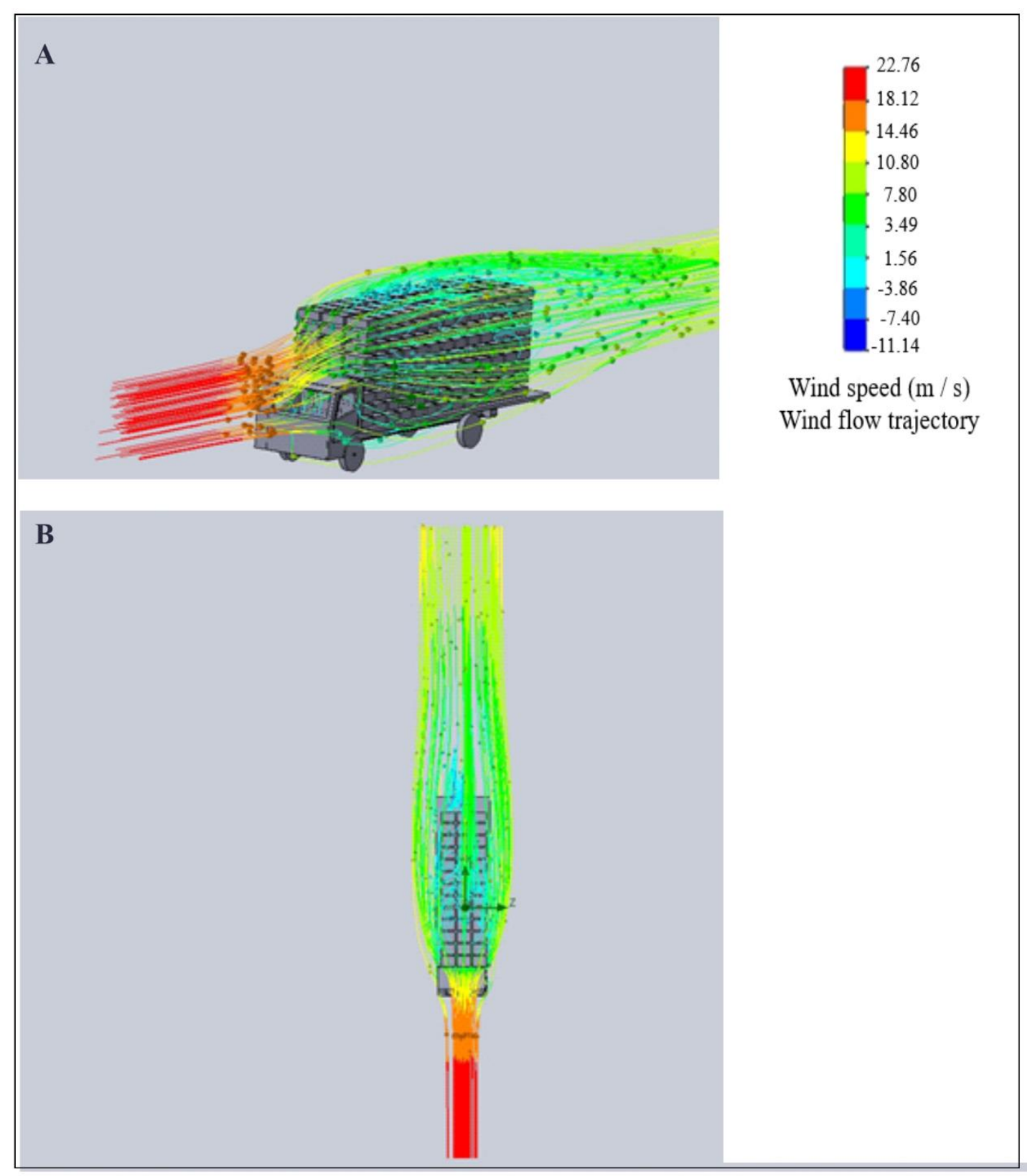

FIGURE 6. Ventilation pattern in the load of the alternative layout (LA) proposed for the transport of broilers, (A) front and side view, (B) top view.

The results indicate that the use of the spacer devices in the TL provided the largest displacement of airflow into the load. One can observe, for example, the predominance of the turbulent flow regime, proven by the negative values observed in Figure 6. This behavior can have a positive influence on the health and welfare of chickens because it enhances the process of heat transfer by the convection of birds owing to its contribution to greater air renewal, and consequently, a reduction in the saturated environment, resulting from the panting of the birds (Barbosa-Filho et al., 2009) as well as by the humidity caused by wetting the load before loading, which is a typical practice in countries with a tropical climate (Pinheiro et al., 2020).

Santos et al. (2020) evaluated the microclimate of the load during the transport of live chickens in Brazil during two typically different seasons, i.e., the dry (June to September) and rainy (November to January) seasons, and two transport distances (15 and $90 \mathrm{~km})$. The authors monitored 12 shipments and found that the dry season is the most critical period for broiler transport and that mortality during the rainy season was not significantly different between distances. However, during the dry season, the DOA was significantly higher on trips covering $90 \mathrm{~km}$ owing to the thermal stress. Therefore, the results of this study are of potential interest to the poultry sector as well as companies specialized in the transport of broiler chickens because the cargo environment is one of the main problems faced during transport.

\section{Wind tunnel tests}

A gradual increase in ventilation inside the crates (VIC) was observed with an increase in test speed (Figure 7). Wind tunnel tests with "empty" crates used for transport of broiler chickens showed that the use of spacers in the LA model provided a higher VIC $(\mathrm{P}<0.05)$ with a speed of 15 $\mathrm{m} / \mathrm{s}$ (Figure 8). However, with the "filled" crates, at a density of eight birds/crate, the VIC results were below the 
measurement sensitivity of the devices used in this study $(0.001 \mathrm{~m} / \mathrm{s})$, suggesting practically insignificant values of ventilation inside the transport crates. This highlights the existence of barriers to efficient air circulation in the crates, which can be related to their design and not only the external circulation areas. This indicates an important new parameter in the search for better conditions for thermal comfort during chicken transport, i.e., the aerodynamics of the crates, which should involve efficient openings without a loss in the mechanical resistance during stacking and transport.

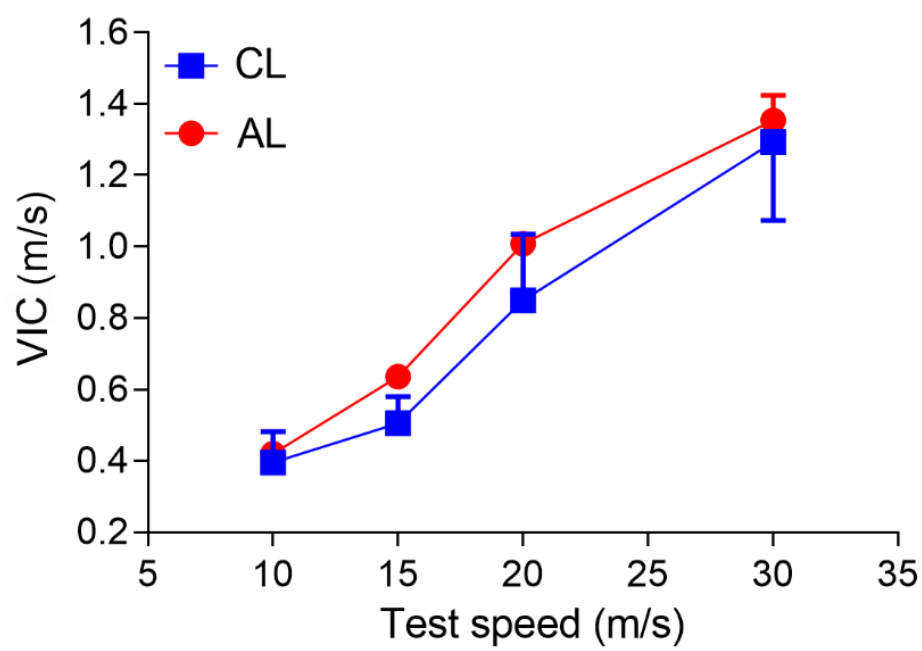

FIGURE 7. Variation of ventilation inside the crates (VIC) \pm standard error of the mean as a function of the test speed in the wind tunnel in the conventional (CL) and alternative (AL) layout.

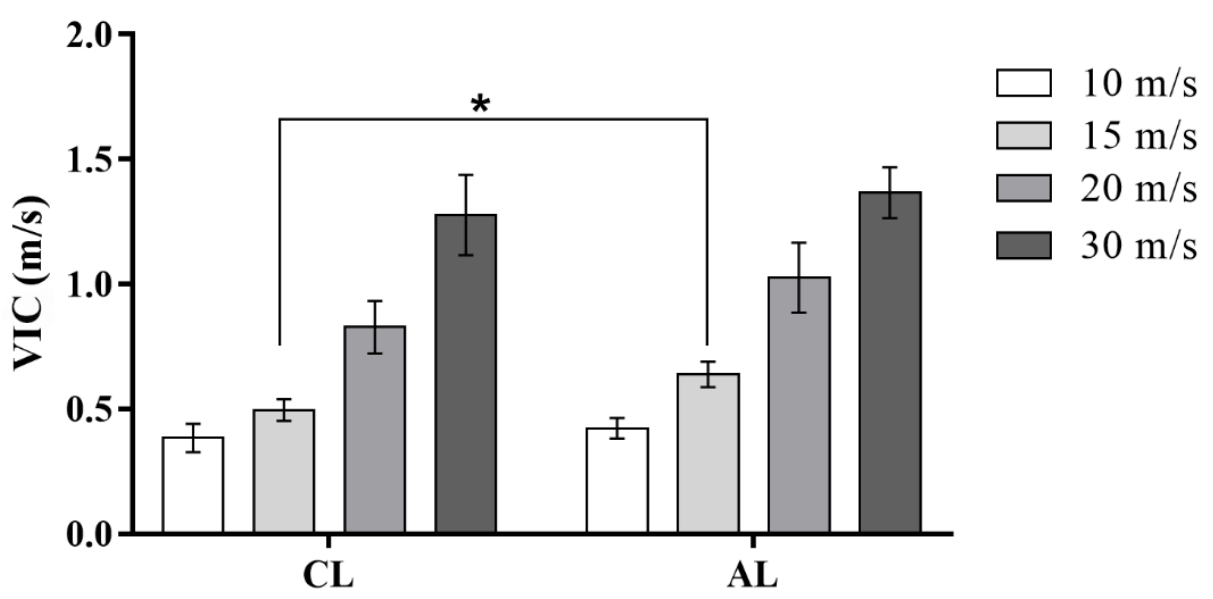

FIGURE 8. Variation of ventilation inside the crates (VIC) \pm standard error of the mean as a function of the wind tunnel test speed in the conventional (CL) and alternative (AL) layout. * Means differ from each other using the Kruskal Wallis test (P <0.05).

Based on the results, it can also be seen that the VIC and bird density in the transport crates are inversely proportional. It is also worth noting that, although the creation of ventilation corridors between the transport crates inside the load when using spacer devices in the LA model may contribute to a better environment of the live load through the removal of polluting gases and suspended particles (Seedorf \& Schmidt, 2017), this alone is not a strategy guaranteeing the mitigation of thermal stress of the chickens during transport because the results suggest that ventilation inside the crates was insufficiently minimized.

However, there are several possibilities for achieving a reduced heat stress, such as the use of a low density in the transport crates, as reported by Hussnain et al. (2020), when they evaluated the transport of broiler chickens at different stocking densities (at 10, 12, and 15 birds/crate) during a hot and humid summer in Turkey and observed a significant increase in the percentage of body weight loss $(4.89 \%$ to $6.33 \%)$ and DOAs $(3.33 \%$ to $10.17 \%$ ) with an increase in the density of the crates. However, it should be noted that the use of a low crate density is not feasible for livestock transport logistics in poultry farming because of the freight costs added to the system (Rui et al., 2011).

Another important aspect is related to the design and dimensions of commercially available transport crates, which are already under investigation from the perspective of the impact generated on the animal welfare by the restriction of movement (Vinco et al., 2016). Considering the results of this research, there is evidence that a transport crate is a key element ensuring optimal animal comfort, a reduction in the DOA rate, and bird welfare during transport. Therefore, studies on increasing the aerodynamic and thermal efficiency of chicken transport crates may reduce the economic losses in the production chain. 


\section{CONCLUSIONS}

It was concluded that the use of spacer devices between transport crates, despite modifications to the ventilation patterns in the load, does not promote an efficient ventilation rate within the crates used for transporting broiler chickens. There are indications that the design and aerodynamics of a transport crate are elements that will directly affect the internal ventilation of a load.

\section{ACKNOWLEDGMENTS}

We appreciate the support of the Brazilian National Council for Scientific and Technological Development (CNPq, Portuguese: Conselho Nacional de Desenvolvimento Científico e Tecnológico)

\section{REFERENCES}

Ahmadi R, Sefidvash F (2018) Study of Pressure Drop in Fixed Bed Reactor Using a Computational Fluid Dynamics (CFD) Code ChemEngineering 2:14-40. DOI: https://doi.org/10.3390/chemengineering2020014

Barbosa-Filho JAD, Queiroz MLV, Brasil FD, Vieira FMC, Silva IJ (2014) Transport of broilers: load microclimate during Brazilian summer. Engenharia Agrícola 34:405-412 DOI: https://doi.org/10.1590/S010069162014000300003

Barbosa-Filho JAD, Vieira FMC, Silva IJO, Garcia DB, Silva MAN, Fonseca BHF (2009) Poultry transport: microclimate characterization of the truck during the winter. Revista Brasileira de Zootecnia 3598: 2442-2446. DOI: https://doi.org/https://doi.org/10.1590/S151635982009001200021.

CONTRAN - Conselho Nacional de Trânsito - Brazilian National Traffic Council (2006). Resolution n 210 of 13/11/2006.

Gilkeson CA, Thompson HM, Wilson MCT, Gaskell PH (2016) Quantifying passive ventilation within small livestock trailers using Computational Fluid Dynamics. Computers and Electronics in Agriculture 124:84-99. DOI: https://doi.org/10.1016/j.compag.2016.03.028

Gilkeson CA, Thompson HM, Wilson MCT, Gaskell PH (2009) An experimental and computational study of the aerodynamic and passive ventilation characteristics of small livestock trailers. Journal of Wind Engineering \& Industrial Aerodynamics 97:415-425. DOI: https://doi.org/10.1016/j.jweia.2009.06.004

Gonçalves SA, Ferreira RA, Pereira IG, De Oliveira CC, Amaral PIS, Garbossa CAP, Da Silva Fonseca L (2017) Behavioral and physiological responses of different genetic lines of free-range broiler raised on a semiintensive system. Journal of Animal Behaviour and Biometeorology 5:112-117. DOI: https://doi.org/10.14269/2318-1265/jabb.v5n4p112-117

Hussnain F, Mahmud A, Mehmood S, Jaspal MH (2020) Effect of transportation distance and crating density on pre-slaughter losses and blood biochemical profile in broilers during hot and humid weather. The Turkish Journal of Veterinary and Animal Sciences. 44:418-426. DOI: https://doi.org/10.3906/vet-1905-85
Kettlewell PJ, Hoxey RP, Hampson CJ, Green NR, Veale BM, Mitchell MA (2001) Design and operation of a prototype mechanical ventilation system for livestock transport vehicles. Journal of Agricultural Engineering Research 79: 429-439. DOI:

https://doi.org/10.1006/jaer.2001.0713

Mitchell MA, Kettlewell PJ (1994) Road transportation of broiler chickens: induction of physiological stress. World's Poultry Science Journal 50: 57-59. DOI:

https://doi.org/10.1079/wps19940006

Norton T, Kettlewell P, Mitchell M (2013) A computational analysis of a fully-stocked dual-mode ventilated livestock vehicle during ferry transportation. Computers and Electronics in Agriculture 93: 217-228. DOI: https://doi.org/10.1016/j.compag.2013.02.005

Pinheiro DG, Barbosa-Filho JAD, Machado NAF (2020)

Effect of wetting method on the broiler transport in Brazilian Northeast. Journal of Animal Behaviour and Biometeorology 8:168-173. DOI: https://doi.org/10.31893/jabb.20022

Rui BR, Angrimani DSR, da Silva MAA (2011) Pontos críticos no manejo pré-abate de frango de corte: Jejum, captura, carregamento, transporte e tempo de espera no abatedouro. Ciência Rural 41: 1290-1296. DOI: https://doi.org/10.1590/S0103-84782011005000092

Santos VM, Dallago BSL, Racanicci AMC, Santana ÂP, Cue RI, Bernal FEM (2020) Effect of transportation distances, seasons and crate microclimate on broiler chicken production losses. PLoS One 15:1-22. DOI: https://doi.org/10.1371/journal.pone.0232004

SAS (2012) SAS/STAT® 9.3 User's Guide. Cary, SAS Institute.

Seedorf J, Schmidt RG (2017) The simulated air flow pattern around a moving animal transport vehicle as the basis for a prospective biosecurity risk assessment. Heliyon 3: e00358. DOI: https://doi.org/10.1016/j.heliyon.2017.e00358

Souza-Junior JBF, El-Sabrout K, de Arruda AMV, Costa LLM (2019) Estimating sensible heat loss in laying hens through thermal imaging. Computers and Electronics in Agriculture 166:105038. DOI:

https://doi.org/10.1016/j.compag.2019.105038

Spurio RS, Soares AL, Carvalho RH, Silveira Junior V, Grespan M, Oba A, Shimokomaki M (2016) Improving transport container design to reduce broiler chicken PSE (pale, soft, exudative) meat in Brazil. Animal Science Journal 87: 277-283.DOI: https://doi.org/10.1111/asj.12407

Vieira FMC, Groff PM, Silva IJO, Nazareno AC, Godoy TF, Coutinho LL, Vieira AMC, Silva-Miranda KO (2019) Impact of exposure time to harsh environments on physiology, mortality, and thermal comfort of day-old chickens in a simulated condition of transport.

International Journal of Biometeorology 63:777-785. DOI: https://doi.org/10.1007/s00484-019-01691-4 
Vinco LJ, Archetti IL, Giacomelli S, Lombardi G (2016) Influence of crate height on the welfare of broilers during transport. Journal of Veterinary Behavior 14:28-33. DOI: https://doi.org/10.1016/j.jveb.2016.06.006

White FM (2000) Fluid mechanics. New York, McGrawHill, v.4, p.13.
Wehmann CF, Rocha PAC, Silva MEV, Araújo FAA, Correia DL (2017) Study and application of computational simulation in simple problems of mechanical two fluids and heat transfer - Part II: Classic problems of heat transmission. Revista Brasileira de Ensino de Física. 40:e2313-2- e23139. DOI: https://doi.org/10.1590/1806-9126-rbef-2017-0221. 